\title{
Self care interventions could advance sexual and reproductive health in humanitarian settings
}

\author{
Forcibly displaced people often lack access to adequate sexual and reproductive health services. \\ Carmen Logie and colleagues examine the role of self care interventions in filling the gap
}

I n 2017, the estimated number of people forcibly displaced by conflict and human rights violations increased by 2.9 million $^{1}$ to a record high of 68.5 million people. ${ }^{1}$ Humanitarian crises disrupt communities to such an extent that they require national or international resources and help. ${ }^{12}$ Forcibly displaced people include those who have left their home but have not crossed an international border (internally displaced people); those who have left their country because of persecution, war, and violence (refugees); and people who have applied for sanctuary in another country (asylum seekers). ${ }^{1}$

Self care interventions are strategies by which people can take control of their own health. Self care interventions for sexual and reproductive health include health promotion (eg, HIV self testing), preventing and controlling illness and disease (eg, pre-exposure prophylaxis for HIV prevention), and self treatment and medication (eg, self managed abortion through self administered mifepristone and misoprostol unsupervised by a healthcare provider). ${ }^{3-5}$ Self care interventions may be particularly appropriate for humanitarian crises when countries may lack sufficient

\section{KEY MESSAGES}

- More than 68 million forcibly displaced people globally experience constrained abilities to realise sexual and reproductive health and rights

- Self care interventions, such as HIV self testing, may be particularly relevant in humanitarian settings that lack sufficient trained health workers, have inadequate health infrastructure, and do not have evidence based sexual and reproductive health policies or practices

- The priorities and needs of marginalised populations, such as adolescents and lesbian, gay, bisexual, transgender, and intersex people, are under-represented in sexual and reproductive health and rights research and programmes in humanitarian settings trained health workers, have poorly maintained and unsustainable health infrastructures, and lack evidence based sexual and reproductive health practices and policies. ${ }^{6}$

Most (85\%) forcibly displaced people are accommodated by low and middle income countries. ${ }^{1}$ Sudden and protracted emergencies often lead to the collapse of healthcare systems in affected countries, and overstraining of healthcare systems in the host countries. ${ }^{7}$ This may result in inadequate or interrupted access to sexual and reproductive health services and rights. ${ }^{2-10}$ Uganda, a low income country, provides an example of one such humanitarian crisis. Over a million refugees are now in Uganda. This is the third largest number of refugees accommodated by a single country in the world and the largest number in Africa. ${ }^{11}$ Most refugees are escaping violence from southern Sudan, and are hosted by districts in northern Uganda, a region recovering from a 20 year civil war. Between 2016 and 2018, the number of refugees in Uganda for every 1000 residents almost tripled to $35 .^{11}$ Yet 2018 saw Uganda's lowest ever refugee response funding levels. ${ }^{11}$ International agencies such as Real Medicine Foundation and Médecins Sans Frontières are working with local hospitals in some refugee settlements. Nevertheless, the underfunding of Uganda's refugee response has led to limited investments in sexual and gender based violence prevention and response programmes. $^{11}$

Challenges to achieving sexual and reproductive health and rights in humanitarian settings include increased sexual violence, reduced access to healthcare services, untreated mental health concerns, and breakdown of familial, social, and community networks. ${ }^{34}$ Information about strategies to increase the use of sexual and reproductive health services in humanitarian situations is limited. ${ }^{256}$ Innovative delivery models and research are needed. ${ }^{6}$ Self care interventions show great promise in these challenging conditions. This analysis paper aims to explore the potential of self care for improving sexual and reproductive health in humanitarian crises.

\section{The potential for self care in humanitarian crises}

A recent review of uptake of sexual and reproductive services in humanitarian crises identified gaps in knowledge in several key areas. ${ }^{2}$ For example, scant research has examined prevention of vertical HIV transmission, prevention and treatment of sexually transmitted infections, abortion and post-abortion care, or clinical management of rape. ${ }^{2}$ The Inter-Agency Working Group on Reproductive Health in Crises $^{12}$ is a coalition of 20 steering committee member agencies. These include the World Health Organization, United Nations agencies, governmental and nongovernmental organisations, researchers, and donor agencies. They defined a minimum initial service package for reproductive health in humanitarian crises, which focuses on priorities for action at the onset of a humanitarian response to an emergency. ${ }^{1213}$ Implementation and use of the minimum initial service package has yet to be systematically evaluated. ${ }^{2}$ It is recommended that introduction of the sexual and reproductive health programme is undertaken by partnerships between the government, private sector, local and international non-governmental organisations, civil society groups, and other groups.

Researchers have called for the adaptation of innovative sexual and reproductive health service delivery models for humanitarian contexts to deal with a range of concerns and barriers. ${ }^{6}$ Systematic reviews suggest that lay health workers are effective in increasing uptake of sexual and reproductive health services in such conditions. ${ }^{2}$ Lay health workers are people who share experiences, such as sex work or displacement, with a community and are trained by health providers. Self care interventions offer an opportunity to increase the capacity of lay health workers and compensate for the shortage of formally trained workers. Refugee lay health workers, for example, 
could be trained to promote and provide information and instructions about self care to other refugees. This might increase uptake of new methods, such as HIV self testing, and improve linkage to care.

Barriers for HIV testing among refugees include shortage of time owing to prioritisation of survival needs, such as food and shelter, over healthcare appointments. ${ }^{14}$ Refugees, particularly adolescents, value privacy to access HIV and other sexual and reproductive health services. ${ }^{615}$ Preferences for convenience and privacy ${ }^{12}$ have generally not been incorporated in HIV interventions for people who have been forcibly displaced. HIV self testing is low cost, and requires a person to collect their own specimen (blood or saliva), conduct the test, and interpret the results. A 2017 systematic review and metaanalysis compared self testing with standard HIV testing among men. It found that self tests increased testing uptake and frequency compared with standard HIV testing, and was associated with a higher likelihood of an HIV positive diagnosis. ${ }^{15}$ HIV self testing in humanitarian settings may reduce barriers to testing, such as stigma, and lack of privacy and confidentiality, ${ }^{13}{ }^{14}$ and may be more convenient than testing in clinics. ${ }^{14}$ Yet preferences for, and feasibility of, HIV self testing remain unexplored in humanitarian crises.

It is tempting to focus on the performance of a new method. However, it is important that any self care intervention considers the environment in which it is being introduced. For example, focusing on adherence to antiretroviral therapy is not helpful when there is no access to, or a lack of stock of, antiretroviral drugs. The safe disposal of testing kits and the security of protected health information are other aspects that must be considered. Training needs, language barriers, and literacy levels among refugees and healthcare providers also need to be assessed.

\section{Intersectional identities among marginalised forcibly displaced people}

"Intersectionality" is a critical feminist theory. It describes how social identities interact and produce different experiences of power and marginalisation. ${ }^{16}$ For instance, young women living in poverty experience age, gender, and class related social and health inequities. For already marginalised people, this may exacerbate barriers to healthcare access. A systematic review $^{9}$ of sexual and reproductive health interventions in humanitarian crises has shown that there is a dearth of tailored strategies for marginalised people such as adolescents, sex workers, lesbian, gay, bisexual, transgender, and intersex (LGBTI) people, and those with disabilities.

The perspectives of adolescents on sexual and reproductive health in humanitarian settings are notably absent and raised as a concern in systematic reviews. ${ }^{2410}$ Most forcibly displaced people are women and children. ${ }^{1}$ Adolescent girls, in particular, face a number of social drivers that lead to poor sexual and reproductive health, such as unwanted pregnancy and HIV infection. These social drivers include, cultural, legal, and economic disadvantages that limit access to sexual and reproductive health services. ${ }^{2410}$ Self care interventions, such as over-the-counter oral contraceptives and HIV self testing, could increase the autonomy of adolescent girls and their access to care by reducing barriers, such as the need for parental consent, stigma, confidentiality concerns in small communities, and the need to travel to a clinic. Research is limited. Exploration of the preferences and concerns of forcibly displaced adolescent girls is needed to develop self care strategies that meet their sexual and reproductive health needs. Adolescent boys are often not included in published reports. They may have different perspectives and priorities than girls. Mixed methods research to ascertain adolescents' knowledge, values, and preferences for sexual and reproductive self care can shape self care interventions.

The sexual health and rights needs and the uptake of services by LGBTI people are underexplored in humanitarian situations. It is difficult to ascertain the prevalence of LGBTI people as this information is not routinely collected. Stigma and the criminalisation of same sex practices are found in 71 countries. This may be the reason for the lack of systematic data collection of sexual orientation and gender identity among refugees and displaced people. Global population based estimates suggest that $1.2-3.5 \%$ of the population is lesbian, gay, or bisexual. ${ }^{17}$ Thus, there may be at least 820000 sexually diverse forcibly displaced people. This number will be larger when people who are transgender and intersex are included. LGBTI people in humanitarian settings may experience barriers to healthcare ${ }^{18}$ owing to stigmatising social norms, healthcare discrimination, and a lack of inclusion in information and resources. For instance, the minimum initial service package does not mention the needs of people who are LGBTI, and its discussion of sexual violence focuses on the needs of cisgender, heterosexual women.
No recent systematic review ${ }^{245}$ has identified an intervention that deals with the sexual and reproductive health needs of LGBTI people in humanitarian situations. LGBTI people often experience stigma and discrimination when attempting to access HIV testing, condoms, lubricant, and tailored safer sex information. Displaced LGBTI and other gender non-conforming people may be at increased risk of sexual violence. This has been reported among internally displaced people in Haiti. ${ }^{19}$ Self care interventions could offer confidential and accessible information for this important group. For example, tailored information could be shared on mobile phone apps. Gaps in information exist about the knowledge, priorities, and preferences for self care of forcibly displaced LGBTI people. Such information could be used to design and implement tailored self care. In addition to self care, structural changes are required to deal with the needs of LGBTI people in the minimum initial service package and comprehensive sexual and reproductive health programmes. For instance, LGBTI affirmative training could be provided for healthcare providers.

\section{Ways forward}

The potential for self care to augment sexual and reproductive care in humanitarian contexts is underexplored. We are not arguing that it is unnecessary to build and fund quality healthcare systems in such situations. On the contrary, many self care interventions require strong and long term links with healthcare systems. However, self care requires less health infrastructure. It can be scaled up more easily than clinic based approaches, and can also avoid concerns about privacy and confidentiality. This is particularly true for refugees, such as adolescents and LGBTI people, who may experience stigma and discrimination.

Intersectional approaches to self care that consider social and structural inequalities are vital. They will help to ensure that we understand diverse preferences for self care interventions and how these may vary by gender, age, and sexual orientation. In humanitarian crises, an understanding of intersectionality will help to ensure that the most marginalised, and often most vulnerable, displaced people have access to sexual and reproductive healthcare interventions. Without this understanding, the sexual and reproductive healthcare provided may not meet the specific needs of diverse refugees.

Good quality research is needed. This should include mixed methods ${ }^{2}$ and 
implementation research, to explore the values, preferences, feasibility, and priorities for self care interventions for sexual and reproductive health. Long term qualitative and ethnographic research is needed to understand which interventions work, and how to ensure that services remain flexible and adaptable to changing and diverse needs. Such research requires financial and technical resources. In addition to soliciting research funding from local and international governmental and non-governmental organisations and the private sector, researchers can work with data collected from routine health services and humanitarian programming initiatives. ${ }^{4}$ There are underexplored possibilities for self care to advance sexual and reproductive health among over 68 million displaced people across the globe through increased healthcare access, privacy, and autonomy.

Contributors and sources:The author group spans a wide range of expertise from social sciences (CHL, MO), public health (KK, SFR), medicine (FS), nursing (HM), and community health (CUK), and each author has worked with forcibly displaced people in Haiti, Uganda, Afghanistan, Turkey, Palestine, and Bangladesh. Sources of information for this article include primary research, systematic reviews, and policy and practice documents. All authors contributed to drafting and editing this manuscript, with CHL taking the lead role. She is also the guarantor of the manuscript. Each author provided intellectual input to improve the manuscript and read and approved the final version.

Competing interests: We have read and understood BMJ policy on declaration of interests and have no relevant interests to declare.

Provenance and peer review: Commissioned; externally peer reviewed.

This article is part of a series proposed by the UNDP/ UNFPA/Unicef/WHO/World Bank Special Programme for Human Reproduction (HRP) and commissioned by The BMJ. The BMJ retained full editorial control over external peer review, editing, and publication of these articles. Open access fees are funded by HRP.

Carmen H Logie, associate professor $r^{1,2}$

Kaveh Khoshnood, associate professor ${ }^{3}$

Moses Okumu, doctoral student ${ }^{1}$

Sabina Faiz Rashid, dean ${ }^{4}$

Fidan Senova, sexual and reproductive health educator ${ }^{5}$

Hamza Meghari, graduate student ${ }^{6}$
Claire Uwase Kipenda, community health worker ${ }^{7}$

${ }^{1}$ Factor-Inwentash Faculty of Social Work, University of Toronto, Toronto, ON, Canada

${ }^{2}$ Women's College Research Institute, Women's College Hospital, Toronto, ON, Canada

${ }^{3}$ Yale School of Public Health, New Haven, CT, USA

${ }^{4}$ James P Grant School of Public Health, BRAC

University, Dhaka, Bangladesh

${ }^{5}$ Çukurova University Faculty of Medicine, Balcalı Hospital, Adana, Turkey

${ }^{6}$ Institute for Global Health, University College London, London, UK

${ }^{7}$ Interaid Uganda, Kampala, Uganda

Correspondence to: C Logie carmen.logie@utoronto.ca

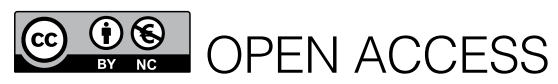

This is an Open Access article distributed under the terms of the Creative Commons Attribution IGO License (https://creativecommons.org/licenses/ by-nc/3.0/igo/), which permits use, distribution, and reproduction for non-commercial purposes in any medium, provided the original work is properly cited.

\section{Check for updates}

1 UN Refugee Agency. Global trends: forced displacement in 2017. Geneva, 2018. https://www. unhcr.org/statistics/unhcrstats/5b27be547/unhcrglobal-trends-2017.html.

2 Singh NS, Aryasinghe S, Smith J, Khosla R, Say L, Blanchet K. A long way to go: a systematic review to assess the utilisation of sexual and reproductive health services during humanitarian crises. BMJ Glob Health 2018;3:e000682. doi:10.1136/ bmjgh-2017-000682

3 World health organization. Ethical, legal, human rights and social accountability of self-initiated interventions. WHO, 2018.

4 Donovan MK. Self-Managed Medication Abortion: Expanding the Available Options for U.S. Abortion Care. Guttmacher Policy Rev 2018;21:41-7. https:// www.guttmacher.org/sites/default/files/article_files/ gpr2104118.pdf

5 World Health Organization. Health worker roles in providing safe abortion care and postabortion contraception. WHO, Geneva, 2015. https://apps.who.int/iris/bitstream/hand le/10665/181041/9789241549264_eng.pdf;jsess ionid=693BD713983FB47DEFAAA8A7BD98A383?s equence $=1$

6 Chamla D, Luo C, Idele P. Children, HIV, emergencies and Sustainable Development Goals: roadblocks ahead and possible solutions. I Int AIDS Soc 2018;21(Suppl 1):e25046. doi:10.1002/ jia2.25046

7 Spiegel PB. The humanitarian system is not just broke, but broken: recommendations for future humanitarian action. Lancet 2017;6736:1-8. doi:10.1016/S0140-6736(17)31278-3

8 Blanchet K, Ramesh A, Frison S, et al. Evidence on public health interventions in humanitarian crises. Lancet 2017;390:2287-96. doi:10.1016/S01406736(16)30768-1

9 Singh NS, Smith J, Aryasinghe S, Khosla R, Say $L$, Blanchet K. Evaluating the effectiveness of sexual and reproductive health services during humanitarian crises: A systematic review. PLoS One 2018;13:e0199300. doi:10.1371/journal. pone.0199300

10 Warren E, Post N, Hossain M, Blanchet K, Roberts B. Systematic review of the evidence on the effectiveness of sexual and reproductive health interventions in humanitarian crises. BMJ Open 2015;5:e008226. doi:10.1136/ bmjopen-2015-008226

11 UNHCR. Uganda country refugee response plan. UNHCR, Nairobi, 2019. https://data2.unhcr.org/en/ documents/download/67314

12 Inter-Agency Working Group on Reproductive Health in Refugee Situations. Minimum initial service package (MISP) for reproductive health in crisis situations: a distance learning module, 2011. http:// www.unhcr.org/4e8d6b3b14.pdf

13 Casey SE. Evaluations of reproductive health programs in humanitarian settings: a systematic review. Confl Health 2015;9:S1. doi:10.1186/1752 1505-9-S1-S1

14 O'Laughlin KN, Rouhani SA, Faustin ZM, Ware NC. Testing experiences of HIV positive refugees in Nakivale refugee settlement in Uganda: informing interventions to encourage priority shifting. Confl Health 2013;7:2. doi:10.1186/1752-1505-7-2

15 Johnson CC, Kennedy C, Fonner V, et al. Examining the effects of HIV self-testing compared to standard HIV testing services: a systematic review and meta-analysis. J Int AIDS Soc 2017;20:21594. doi:10.7448/IAS.20.1.21594

16 Logie CH, Daniel C, Ahmed U, Lash R. 'Life under the tent is not safe, especially for young women': understanding intersectional violence among internally displaced youth in Leogane, Haiti. Glob Health Action 2016;10(suppl 2):1270816. doi:10.1 080/16549716.2017.1270816

17 Gates G. How many people are lesbian, gay, bisexual and transgender. The Williams Institute, 2011. https://williamsinstitute.law.ucla.edu/wp-content/ uploads/Gates-How-Many-People-LGBT-Apr-2011. pdf

18 Spiegel PB, Schilperoord M, Dahab M. High-risk sex and displacement among refugees and surrounding populations in 10 countries: the need for integrating interventions. AIDS 2014;28:761-71. doi:10.1097/ QAD.0000000000000118

19 Ghose T, Boucicaut E, King C, Doyle A, Shubert V. Surviving the aftershock: postearthquake access and adherence to HIV treatment among Haiti's tent residents. Qual Health Res 2013;23:495-506. doi:10.1177/1049732312469463

Cite this as: BMJ 2019;365:11083 http://dx.doi.org/10.1136/bmj.l1083 